\title{
Uso da Gliricidia sepium ((Jacq.) Steud.) em substituição da soja no manejo alimentar de frangos de corte
}

\author{
Thatiane Lourenço da Silva ${ }^{1}$, Werley Daniel da Silva ${ }^{2}$, Valmir de Lima Gomes ${ }^{3}$, Rivanildo Filgueira dos Santos ${ }^{4}$, \\ Andreza Aguiar Fernandes de Lima ${ }^{5}$, Vanessa Gregório de Assis ${ }^{6}$, Rener Luciano de Souza Ferraz ${ }^{7}$ * \\ Universidade Estadual da Paraíba, ${ }^{1}$ lourencothah@gmail.com; ${ }^{2}$ danieldamoto@gmail.com; \\ ${ }^{3}$ valmir.agrocenter@hotmail.com; ${ }^{4}$ rivanildofilgueira@gmail.com; ${ }^{5}$ andrezaafl@gmail.com; \\ vanessagregorio898@gmail.com; ${ }^{7}$ ferragroestat@gmail.com.
}

\begin{abstract}
RESUMO: A Gliricidia tem se destacado como uma planta forrageira que pode ser introduzida na alimentação animal, pois possui um bom teor proteico que pode chegar até $30 \%$ de proteína bruta. O presente trabalho visa relatar a experiência realizada na disciplina de Projetos Agropecuários do Curso Técnico em Agropecuária da Escola Assis Chateaubriand no campus II da Universidade Estadual da Paraíba, visando despertar nos alunos a importância de buscar práticas alternativas de alimentação que venham a contribuir com o desenvolvimento das aves de corte em confinamento.
\end{abstract}

PALAVRAS-CHAVE: Gliricidia; Alimentação; Práticas alternativas.

\section{CONTEXTO}

A avicultura é um dos segmentos que mais cresce no país. Para Duarte Talamini et al. (2018), o grande desenvolvimento da atividade e o sucesso alcançado tanto na produção como no acesso aos mercados são fatores que garantem tal crescimento que cada vez mais traz melhorias econômicas para o produtor e consequentemente para o país. De acordo com Canevari Bruno et al. (2012), a necessidade por melhorias no seguimento são constantes, sempre visando o melhoramento genético e uma boa nutrição, pois dessa maneira é possível garantir que seu desenvolvimento das aves sejam satisfatório ao longo de todo ciclo.

Salienta-se que a dieta da ave deve ser balanceada para que possa fornecer todos os nutrientes essenciais para seu crescimento e assim seja possível atingir as mais variáveis metas, como por exemplo, a consistência de carcaça, o peso final entre outros. Pesquisas na área tem avançada cada vez mais para que seja possível obter uma alimentação que possua baixo custo e ao mesmo tempo satisfaça as necessidades das aves e seu desempenho Zanardo Donato et al. (2011).

O uso do farelo de soja é muito comum na formulação da ração das aves de corte, a exigência do mercado, principalmente o europeu, fez com que o uso da soja fosse mais valorizado e consequentemente mais usado. A soja é responsável por oferecer ao animal um elevado teor proteico, permitindo que seja um dos componentes presentes no balanceamento da ração e que junto com outros elementos, como por exemplo, os aminoácidos que estão presentes na soja permitirá atender as exigências da composição do farelo de soja sobre o desempenho e o metabolismo de frangos de cortes ias nutricionais e garantir uma melhor eficiência no ganho de peso das aves, Pigatto Gerber et al. (2006).

Buscando alternativa que venha a contribuir com a formulação de ração, viu-se na gliricidia a possibilidade de explorar seu teor nutritivo e energético. A gliricídia é uma planta nativa do México que se adaptou muito bem a região do nordeste brasileiro e é usada como alternativa de forragem na alimentação de animais ruminantes, pois possui um teor de proteína bruta que pode chegar até $30 \%$ como destaca Santos Neto et al. (2017). Todavia não se tem relatos de seu uso na alimentação de animais monogástricos, mais precisamente em frangos de corte.

Nesse contexto, visando encontrar meios que possibilite o desenvolvimento das aves, foi utilizado a gliricidia como parte da ração oferecida para saber se é possível sua inserção como parte da alimentação.

\section{DESCRIÇÃO DA EXPERIÊNCIA}

Durante a disciplina de Projetos Agropecuários ofertada na grade curricular do curso Técnico em Agropecuária da Escola Agrícola Assis Chateaubriand, no campus II da UEPB, foi pensado um meio que facilitasse o manejo alimentar de frango de corte e pudesse ao mesmo tempo substituir parte da soja que é um dos componentes mais utilizados na composição de ração para aves em geral.

A princípio, pensou-se em usar a Moringa oleifera Lamarck, outra planta forrageira que é bem aceita na alimentação de animais ruminantes, entretanto, observou-se que não era possível a oferta devido à quantidade necessária que não seria suficiente para atender a demanda durante todo o ciclo de manejo das aves.

Já que o uso da Moringa oleífera Lamarck não foi possível, substitui-se pela Gliricidia sepium ((Jacq.) Steud.), pois a mesma é acessível e teria quantidade suficiente para atender o manejo durante todas as etapas. 
SILVA, T. L. et al. Uso da Gliricidia sepium ((Jacq.) Steud.) em substituição da soja no manejo alimentar de frangos de corte. In: II Congresso Paraibano de Agroecologia \& IV Exposição Tecnológica, 2019. Anais... Caderno Verde de Agroecologia e Desenvolvimento Sustentável, Pombal, v. 9, n.7, e-7073, 2019.

A ideia foi apresentada a direção da escola que permitiu tal realização dentro da instituição. O experimento foi realizado num prazo de 60 dias, no qual, os primeiros 12 dias foram para organizar o ambiente onde as aves iam ficar além do tempo necessário para que a gliricidia pudesse perder umidade e ser triturada.

O espaço usado foi o do setor de coturnicultura, que no momento estava vazio, foram realizados todos os procedimentos para um garantir um bom manejo desde a recepção até o abate. Os alunos, trabalharam em equipe para montar todo o espaço que foi dividido em 4 células para que pudesse atender o experimento, como mostra a figura 1.

\section{Figura 1}

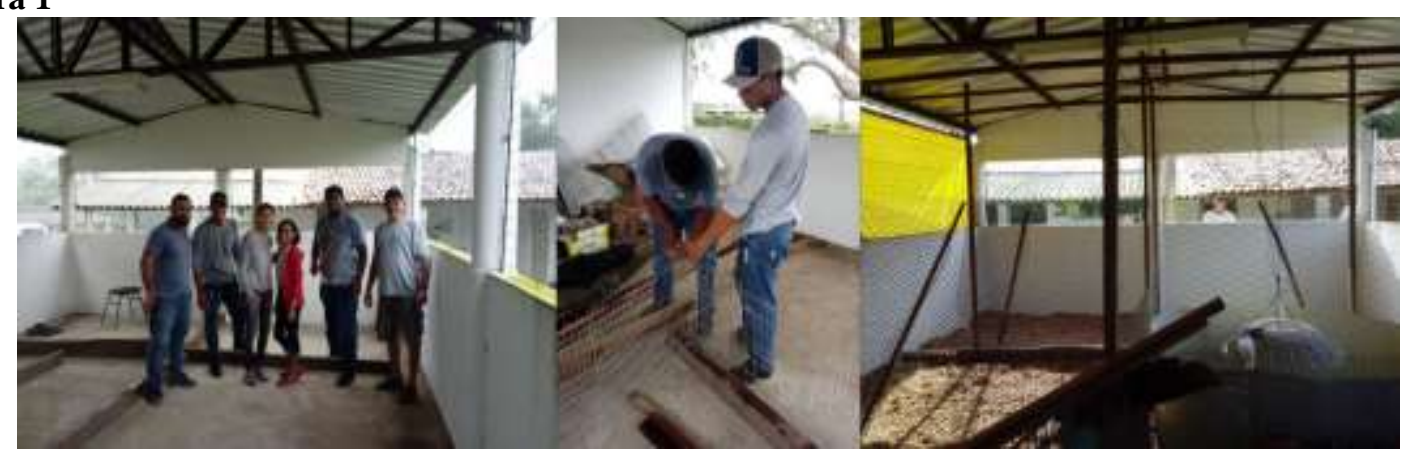

O passo seguinte, pós-divisão das células, foi prepara a lona para fazer as cortinas que ia servir de quebra vento e colocar o bagaço de cana de açúcar para montar a cama de frango e assim forrar o piso onde as aves iam permanecer durante todo o experimento, (figura 2).

Figura 2

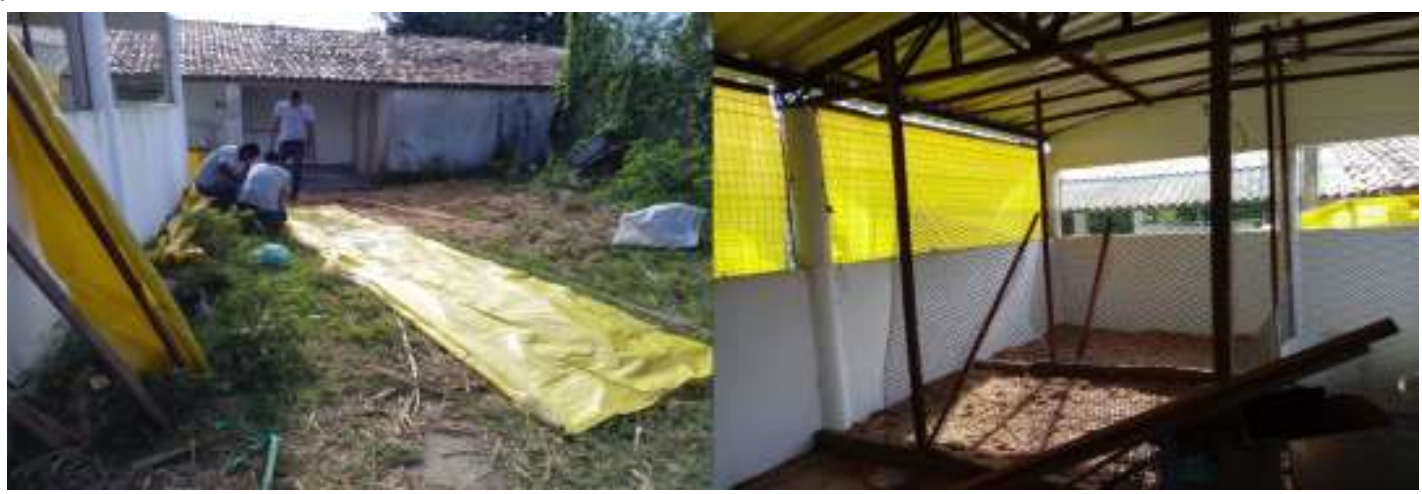

Para atender as necessidades iniciais das aves foram usados 3 bebedouros de pressão, 3 comedouros tubulares, 1 aquecedor, 1 lâmpada alógena e um termômetro (figura 3). Passado os 15 dias iniciais os comedouros e bebedouros foram substituídos, por bebedouros semi-automáticos e bebedouros tubular, ficando um de cada em cada célula onde estavam divididos as aves (figura 3).

\section{Figura 3}

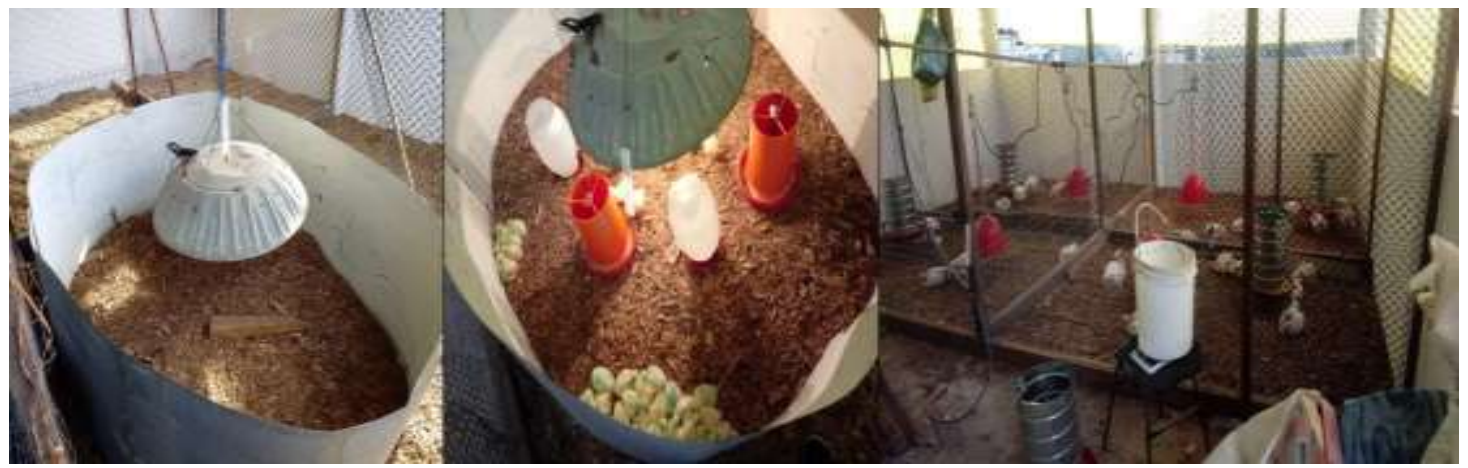

A ração era preparada para cada fase nos níveis propostos no experimento (figura 4), com as porcentagens de $0 \%$ gliricidia; $2,5 \%$ gliricidia, 5,0\% e 7,5\%, em seguida era colocadas em sacos que continha as respectivas descrições. 
SILVA, T. L. et al. Uso da Gliricidia sepium ((Jacq.) Steud.) em substituição da soja no manejo alimentar de frangos de corte. In: II Congresso Paraibano de Agroecologia \& IV Exposição Tecnológica, 2019. Anais... Caderno Verde de Agroecologia e Desenvolvimento Sustentável, Pombal, v. 9, n.7, e-7073, 2019.

\section{Figura 4}

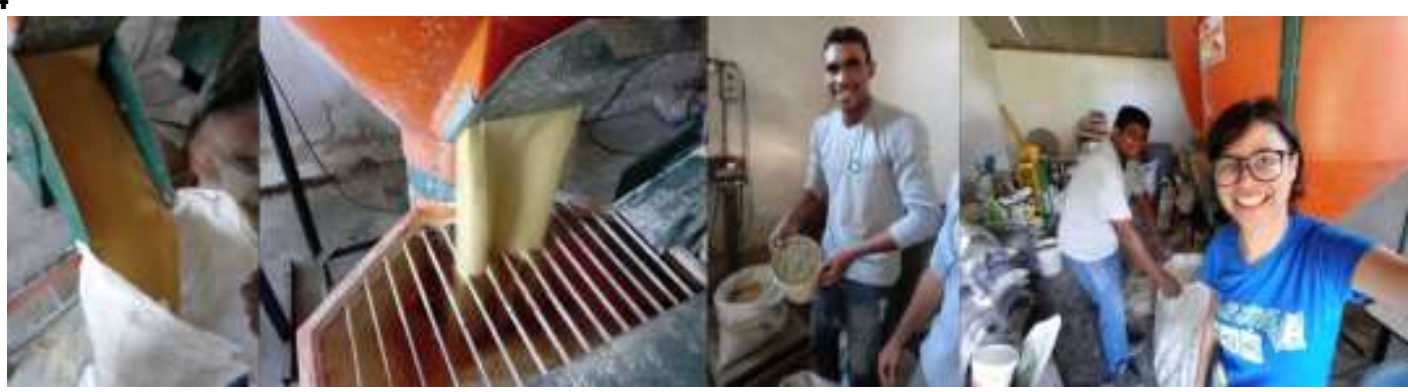

Passado os primeiros 15 dias, as aves foram divididas em 4 grupos (figura 5) que receberiam na ração quantidades diferentes de gliricidia. Os grupos estavam na seguinte ordem: $0 \%$ gliricidia, ou seja, a composição da ração era com a presença da soja $100 \%$; 2,5 gliricidia e $97,5 \%$ de soja; $5,0 \%$ de gliricidia e $95 \%$ de soja e $7,5 \%$ de gliricidia e $92,5 \%$ de soja. Salienta-se que a ração completa ainda dispunha em sua composição, óleo de soja, farelo de milho, núcleo, fosfato de cálcio, metionina e creonina.

\section{Figura 5}

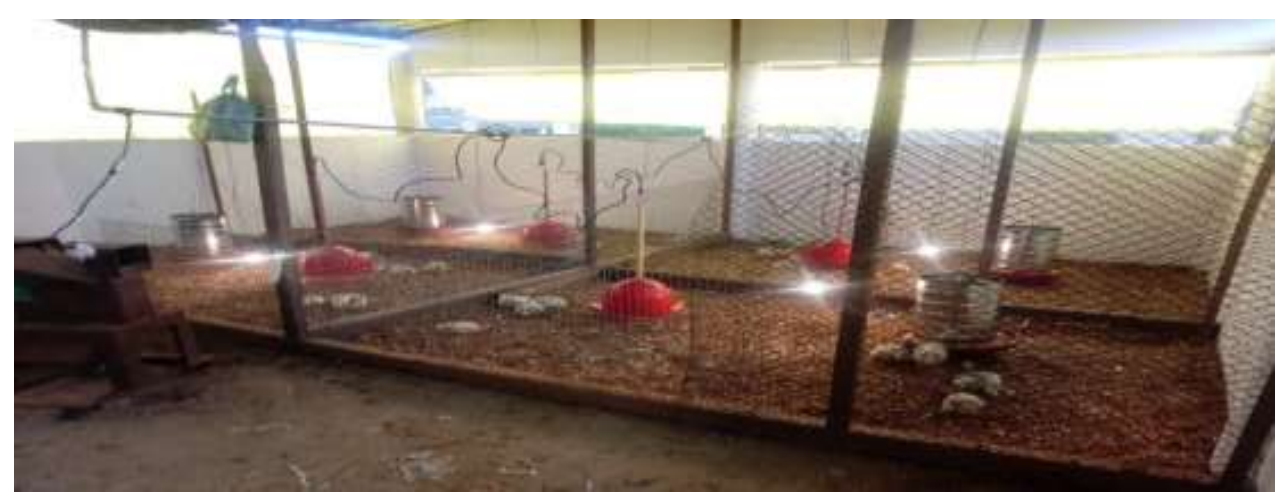

Ao passo que iam se desenvolvendo os níveis de ração foram sendo alterados para satisfazer as suas necessidades de crescimento. Nos primeiros15 dias, a ração oferecida foi a inicial, onde todos os pintinhos receberam a mesma ração, passados os 15 dias iniciais foram divididos para suas respectivas células e passaram a receber a ração de crescimento, quando completou 40 dias de experimento a ração passou a ser a de fase final, entretanto os valores de soja e gliricidia permaneceram os mesmos.

Durante o experimento ocorreu um leve quadro de infecção respiratória que foi tratado com alho (figura 6), vindo a ser sanada num curto espaço de tempo, não ocasionado nenhuma perda e restabelecendo a sanidade das aves.

\section{Figura 6}

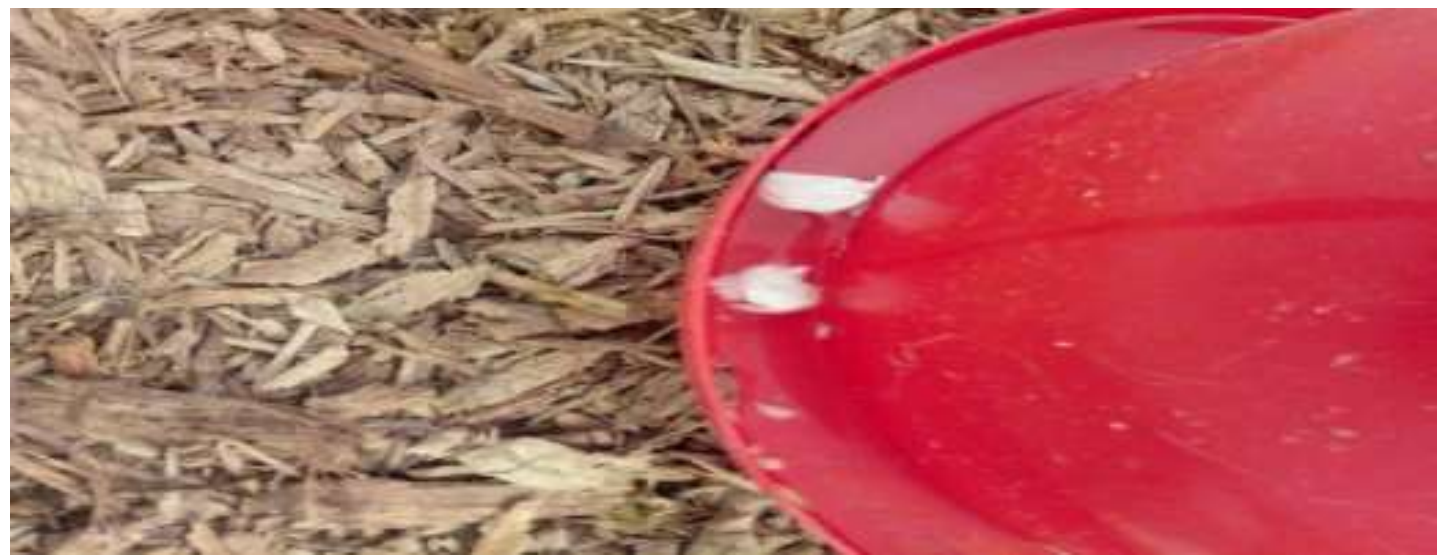

Passados os 45 dias de experimento, as aves estavam prontas para abate, entretanto devido ao espaço para realização de tal atividade ficou inviável fazer dentro o prazo pensado a princípio, sendo prorrogado mais três dias para ao abate, como mostra a imagem 7. 
SILVA, T. L. et al. Uso da Gliricidia sepium ((Jacq.) Steud.) em substituição da soja no manejo alimentar de frangos de corte. In: II Congresso Paraibano de Agroecologia \& IV Exposição Tecnológica, 2019. Anais... Caderno Verde de Agroecologia e Desenvolvimento Sustentável, Pombal, v. 9, n.7, e-7073, 2019.

Figura 7

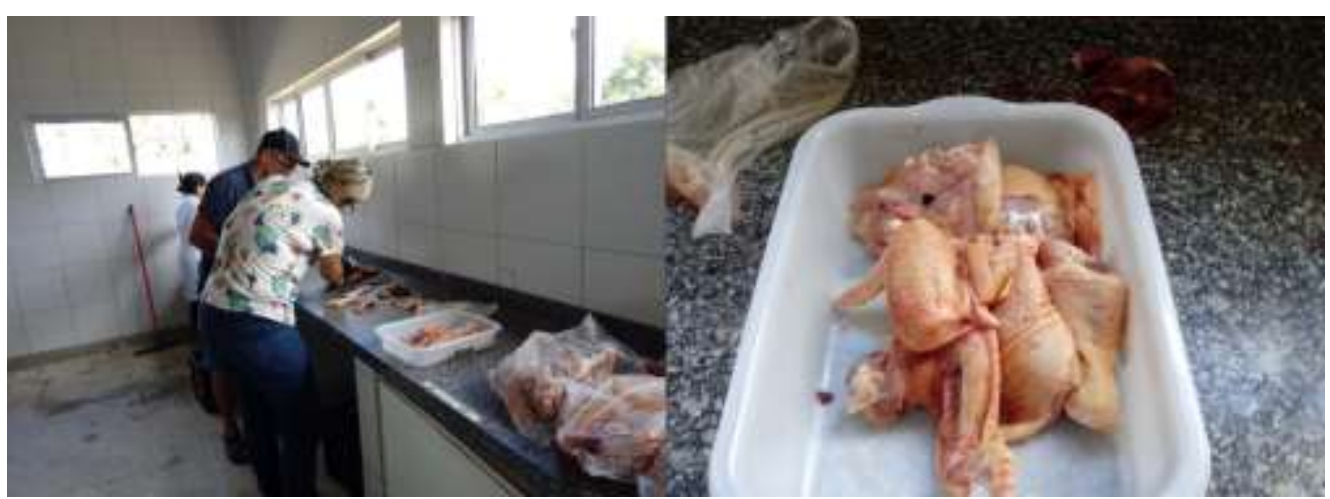

\section{RESULTADOS}

Após 48 dias de manejo, foi possível observar que as aves que receberam o tratamento de gliricidia na ração se desenvolveram tão bem como as aves que tinha sua ração formulada com 100\% de soja na sua composição.

Dessa forma os resultados são positivos ao uso da gliricidia dentro da composição de ração para aves de cortes, podendo ser usada sem causar nenhum dano à ave. O desenvolvimento obtido nas aves que receberam nos tratamentos quantidades de gliricidia se assemelha aos das aves que receberam a soja $100 \%$ como parte da composição da ração.

\section{REFERÊNCIAS}

DRUMOND, M. A.; FILHO, O. M. Introdução e Avaliação da Gliricidia sepium na região semi-árida do Nordeste Brasileiro. Disponível em < https://ainfo.cnptia.embrapa.br/digital/bitstream/item/107419/1/Drumond.pdf >.

NETO, E. B. S.; NASCIMENTO, I. R.; MENEZES, B. F.; IWERSEN, J. C. Avaliação da composição bromatológica da forragem de gliricídia (gliricídia sepium (jacq) Walp) ensilada em saco plástico. In: VI Congresso Latino Americano, X Congresso Brasileiro e V Seminário DF e ENTORNO Brasília. Anais... Brasília VI CLAA, X CBA e V SEMDF Vol. 13, $\mathrm{N}^{\circ} 1$, Jul. 2018.

OLIVEIRA, E. C. de. Valores energéticos do milho e do farelo de soja para aves de diferentes categorias zootécnicas / Evelyn Cristina de Oliveira. - Lavras: UFLA, 2015. 42 p.

TALAMINI. D.J. D.; MARTINS F. M., F.; JONAS I. dos S. Conjuntura econômica da avicultura brasileira em 2018. Disponível em < https://ainfo.cnptia.embrapa.br/digital/bitstream/item/190390/1/final9033.pdf>

GERBER, L. F.P.; JÚNIOR. A. M. P.; RIBEIRO, A. M. L.; Disponível em< http://www.scielo.br/pdf/\%0 D/rbz/ v35n4/15.pdf>

DONATO. D. C. Z.; ALBUQUERQUE. R. d.; GARCIA. P. D. S. R.; BALIEIRO. J. C. d. C.; Desempenho de frangos de corte alimentados com rações contendo diferentes níveis de cálcio suplementadas com fitase1. Disponível em <

\section{AGRADECIMENTOS}

Apoio financeiro: Fundação de Apoio à Pesquisa do Estado da Paraíba - FAPESQ. 